\title{
ANALISIS SISTEM ANTRIAN PADA LOKET PENDAFTARAN PASIEN DI PUSKESMMAS PADANG PASIR KECAMATAN PADANG BARAT
}

\author{
Ali Sutan Nasution ${ }^{1}$, Seira Mutia ${ }^{2}$ \\ Teknik Industri Sekolah Tinggi Teknologi Industri Padang \\ email: ${ }^{1}$ sutan@dutatruckers.com, ${ }^{2}$ seira_mutia@yahoo.com
}

\begin{abstract}
ABSTRAK
Puskesmas Padang Pasir Kecamatan Padang Barat merupakan lembaga pelayanan kesehatan masyarakat yang berada dibawah naungan Dinas Kesehatan Pemerintah Kota Padang yang beralamat JL. Padang Pasir VI No. 1 Padang. Pada sistem loket saat ini terdapat 3 loket yang memakan waktu rata-rata 3 menit per pasien. Hal ini membuat pelayanan pasien diloket memakan waktu cukup lama yang membuat antrian diloket sangat panjang sehingga cukup menghambat pasien untuk berlalu-lalang menuju poli bagian dalam atau pun diluar. Loket pendaftaran termasuk hal yang paling penting dalam pelayanan kesehatan. Dengan lamanya penanganan pasien, maka dengan penelitian ini diusulkan menambah 1 loket lagi untuk mengurangi antrian yang panjang.Untuk itulah penelitian ini menggunakan metode statistik yang bermanfaat untuk menganalisa tingkat kedatangan dan tingkat pelayanan pasien puskesmas. Sedangkan analisis teori antrian digunakan untuk menghitung antrian sistem pelayanan yang optimal berdasarkan tingkat kedatangan dan tingkat pelayanan. Tujuan penggunaan teori antrian ini adalah untuk merancang fasilitas pelayanan dalam mengatasi permintaan pelayanan yang berfluktuasi secara random guna menjaga keseimbangan antara waktu pelayanan dan waktu yang diperlukan selama antrian.Saat kedatangan pasien terbanyak selama waktu penelitian adalah 93 pasien, maka diusulkan untuk menambah 1 loket lagi menjadi 4 loket. Hasil yang diperoleh dengan diusulkan penambahan loket, antrian berkurang menjadi $15,15 \%$.
\end{abstract}

Kata Kunci:Teori Antrian, FCFS, loket, Puskesmas Padang Pasir.

\section{PENDAHULUAN}

Puskesmas Padang Pasir Kecamatan

Padang Barat merupakan lembaga pelayanan kesehatan masyarakat yang berada dibawah naungan Dinas Kesehatan Pemerintah Kota Padang. Setiap pasien datang akan dilayani oleh dokter, bidan dan perawat dimana pasien untuk mendapatkan pelayanan tersebut harus mengantri sehingga diperlukan fasilitas pelayanan yang memadai guna memberikan pelayanan pada pasien. Hal ini menyebabkan fenomena antri menjadi suatu kegiatan yang biasa terjadi dalam kehidupan sehari-hari. Masalah antrian ini menjadi salah satu penyebab persaingan antar tempat pelayanan keseehatan sehingga jika pelayanan kesehatan itu baik maka pasien akan tertarik untuk berobat kembali pada tempat pelayanan kesehatan tersebut.

Sarana pelayanan tahap demi tahap yang diberikan pemerintah pada puskesmas dilakukan demi kepuasan pasien. Akan tetapi, hanya sarana pelayanan saja tidak cukup bagi para pasien yang menunggu terlalu lama untuk ditanggapi keluhan penyakit pasien begitu saja. Yang diinginkan pasien adalah kepuasan pelayanan dan cepat tanggap dengan berbagai macam keluhan penyakit 
dari pasien. Hal ini dapat berpengaruh pada jumlah pasien yang melakukan registrasi.

Pada tabel berikut akan ditampilkan jumlah dan waktu pasien perhari selama penelitian dibawah ini :

Tabel 1. Rangkuman Data Antrian Puskesmas Padang Pasir

\begin{tabular}{|c|c|c|c|}
\hline No & Tanggal & $\begin{array}{c}\text { Jumbh Pasien } \\
\text { Per Hari } \\
\end{array}$ & $\begin{array}{l}\text { Total Waktu Pt } \\
\text { Pasien (Meni) }\end{array}$ \\
\hline 1 & 24-Jul-17 & 86 & 243 \\
\hline 2 & $25-\mathrm{Jul}-17$ & 90 & 240 \\
\hline 3 & $26-541-17$ & 93 & 240 \\
\hline 4 & $27-\mathrm{Jul}-17$ & 81 & 238 \\
\hline 5 & 28-Jul-17 & 86 & 242 \\
\hline 6 & 29-Jul-17 & 73 & 227 \\
\hline 7 & 31-Jul-17 & 92 & 278 \\
\hline 8 & 01-Agust-17 & 87 & 270 \\
\hline 9 & 02-Agust-17 & 84 & 266 \\
\hline 10 & 03-Agust-17 & 78 & 257 \\
\hline
\end{tabular}

Sumber : Puskesmas Padang Pasir

Memperhatikan uraian diatas maka dapat dirumuskan masalah yang melatar belakangi penelitian ini adalah :

1. Berapakah waktu pelayanan yang optimal pada loket pendaftaran pasien di Puskesmas Padang Pasir.

2. Bagaimanakah merancang sistem antrian yang optimal pada loket pendaftaran pasien di Puskesmas Padang Pasir.

Sesuai dengan latar belakang diatas, tujuan penelitian ini adalah merancang sistem antrian yang optimal untuk mengurangi antrian panjang diloket pendaftaran.

\section{METODA PENELITIAN}

Penelitian ini termasuk kedalam jenis penelitian komperatif, yaitu sejenis penelitian deskriptif yang ingin mencari jawaban secara mendasar tentang sebabakibat, dengan menganalisis faktor-faktor penyebab terjadinya ataupun munculnya suatu fenomena tertentu pada masa sekarang. Dan jenis data yang akan menjadi acuan adalah data primer hasil survei lapangan. Data-data tersebut selanjutnya diolah dengan menggunakan metoda statistik dan juga metoda teori antrian M/M/c : FCFS/ / . Penggunaan metoda yang digunakan pada penelitian ini adalah $\mathrm{M} / \mathrm{M} / \mathrm{c}$, bahwa $\mathrm{M}$ menyatakan tentang tingkat dan pelayanan poisson. Model antrian dengan distribusi kedatangan Poisson atau distribusi waktu kedatangan eksponensial. Distribusi waktu pelayanan eksponensial. Sedangkan c menyatakan jumlah saluran pelayanan (Server / Banyaknya Petugas). Berdasarkan penelitian ini dilakukan hanya fokus pada loket pendaftaran dan dilaksanakan saat jam mulai pelayanan sampai akhir waktu pelayanan.

\section{HASIL PENELITIAN DAN PEMBAHASAN}

\subsection{Menghitung Jumlah Petugas Pelayanan}

Perhitungan dibawah ini dilakukan untuk mengetahui waktu rata-rata pelayanan pasien :

$$
X(S i)=\frac{\sum X}{\sum n}
$$

$X(S i)=\frac{150459}{850}$

$X(\mathrm{Si})=177.0105882 \operatorname{detik}(2$ menit 95 detik )

Jadi waktu rata-rata pelayanan petugas untuk pasien adalah 2 menit 95 detik.

Kemudian perhitungan selanjutnaya waktu rata-rata kedatangan pasien :

$$
\begin{aligned}
& X(A i)=\frac{\sum X}{\sum n} \\
& X(A i)=\frac{4475102}{850} \\
& X(A i)=5264.825882 \operatorname{detik}(87
\end{aligned}
$$

menit 74 detik )

Jadi waktu rata-rata kedatangan pasien adalah 87 menit 74 detik.

Perhitungan nilai-nilai dibawah ini didasarkan pada data-data yang telah diperoleh dan diuji distribusi. 
Tabel 2. Distribusi Kedatangan dan Pelayanan

\begin{tabular}{|c|c|c|c|c|c|c|}
\hline No & \multicolumn{2}{|c|}{ Kelas Interval } & $\mathrm{F}$ & $\mathrm{Xh}$ & $\mathrm{Xa}$ & Xi \\
\hline 1 & 61 & 128 & 250 & 0 & 128.5 & 67 \\
\hline 2 & 129 & 196 & 359 & 128.5 & 196.5 & 134 \\
\hline 3 & 197 & 264 & 155 & 1965 & 264.5 & 201 \\
\hline 4 & 265 & 332 & 41 & 264.5 & 332.5 & 268 \\
\hline 5 & 333 & 400 & 22 & 3325 & 4005 & 335 \\
\hline 6 & 401 & 468 & 5 & 400.5 & 468.5 & 402 \\
\hline 7 & 469 & 536 & 7 & 468.5 & 536.5 & 469 \\
\hline 8 & 537 & 604 & 5 & 536.5 & 604.5 & 536 \\
\hline 9 & 605 & 672 & 2 & 6045 & 6725 & 603 \\
\hline 10 & 673 & 740 & 4 & 6725 & 740.5 & 670 \\
\hline & & & 850 & & & 3685 \\
\hline
\end{tabular}

Pengujian distribusi kedatangan dilakukan dengan cara komulatif yang diperoleh dari hasil observasi yang disusun kedalam bentuk distribusi frekuensi yang dilakukan dengan cara seperti berikut :

1. Tentukan rentang ( $r$ ), yaitu data terbesar dikurangi dengan data terkecil

$$
\mathrm{r}=731-61=670
$$

2. Tentukan banyak kelas interval yang diperlukan dengan menggunakan aturan yaitu banyak kelas (k)

$$
\begin{aligned}
\mathrm{k} & =1+3.3 \log \mathrm{n} \\
& =1+3.3 \log 850 \\
& =1+3.3 \times 2.92 \\
& =10
\end{aligned}
$$

Dimana $\mathrm{n}$ menyatakan banyaknya data dari hasil pengamatan.

3. Tentukan kelas interval (p), dengan menggunakan formula berikut :

$$
\begin{aligned}
\mathrm{p} & =\mathrm{r} / \mathrm{k} \\
& =670 / 10 \\
& =67
\end{aligned}
$$

4. Perhitungan uji distribusi frekuensi

$$
\text { a. } \begin{aligned}
X & =\frac{\sum X}{\sum n} \\
X & =148.504 \text { detik } \\
\text { b. } \quad \lambda & =\frac{1}{X} \\
\lambda & =\frac{1}{148.504} \\
\lambda & =0.00673 \text { pasien/detik }
\end{aligned}
$$

$$
\begin{array}{ll}
\text { c. } \quad P_{1}=e^{-\lambda X b}-e^{-\lambda X a} \\
e=2.7183 \\
P_{1}=2.7183^{-0.00673 x 0}-2.7183^{-0.00673 \times 128.5} \\
\rho=0.577 \\
\text { d. } \quad e_{i}=\frac{P_{i}}{\sum P_{i}} \\
e_{i}=\frac{0.577}{1.154} X 850 \\
e_{i}=425
\end{array}
$$

\subsection{Kondisi sekarang terdapat 3 Loket}

Tingkat kedatangan pasien :

$$
\begin{aligned}
\lambda & =0.01346 \text { Pasien/detik } \\
\lambda & =48.45 \text { Pasien/Jam }
\end{aligned}
$$

Tingkat Pelayanan pasien :

$$
\begin{aligned}
& \mu=0.00673 \text { Pasien/detik } \\
& \mu=24.22 \text { Pasien/Jam. }
\end{aligned}
$$

Jumlah pelayanan $(\mathrm{c})=3$ loket

$$
\begin{aligned}
& \rho=\frac{\lambda}{\mu}=\frac{48.45 \text { Pasien } / \text { jam }}{24.22 \text { Pasien } / \mathrm{jam}} \\
& \rho=2.0004128 \\
& \frac{\rho}{c}=\frac{2.0004128}{3}=0.6668
\end{aligned}
$$

1. Probabilitas tidak adanya pasien dalam sistem adalah :

$$
\begin{aligned}
& P_{0}=\left[\sum_{n=0}^{c-1} \frac{\rho^{n}}{n^{!}}+\frac{\left(1-\left(\frac{\rho}{c}\right)\right)}{\left(1-\left(\frac{\rho}{c}\right)\right)}\right] \\
& P_{0}=0.0049989
\end{aligned}
$$

Jadi probabilitas tidak terdapatnya pasien dalam sistem antrian (loket menganggur) adalah 0.0049989 $(0.49989 \%)$

2. Probabilittas sistem penuh

$$
\begin{aligned}
& P_{n}=\frac{\rho^{n}}{n !} P_{0} \\
& P_{93}=\frac{2.0004128^{93}}{93 !} X 0.0049989
\end{aligned}
$$


$P_{93}=4.362721=0.0004362721$

Probabilitas sistem penuh adalah $0.0004362721(0.0436272 \%)$

3. Rata-rata jumlah pasien didalam antrian dilayani adalah 0.870 jam $(52,23$

menit)

\subsection{Sistem Yang Diusulkan (4 loket)}

Tingkat kedatangan pasien :

$\lambda=0.01346$ Pasien/detik

$\lambda=48.45$ Pasien $/ \mathrm{Jam}$

$$
\begin{aligned}
& L q=P_{0} \frac{\rho^{e+1}}{(c-1) !(c-\rho)^{2}}\left\{1-\left(\frac{\rho}{c}\right)^{N-c}-(N-c)\left(\begin{array}{l}
\text { ing } \\
c
\end{array}\right)^{N-c}\left(\begin{array}{l}
\text { pelafahlan pasien : } \\
\mu=0.00673 \text { Pasien/detik }
\end{array}\right.\right. \\
& \mu=24.22 \text { Pasien/Jam. }
\end{aligned}
$$

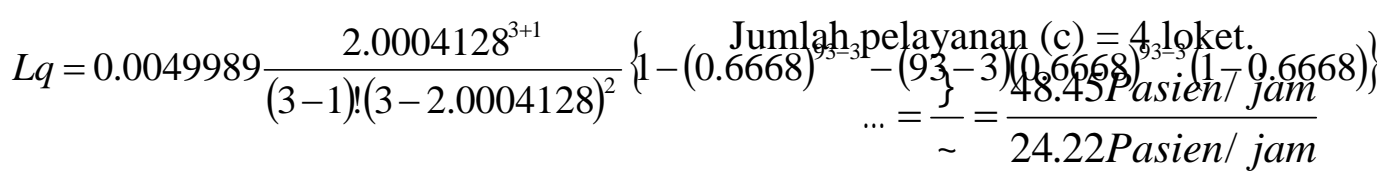

$$
\begin{aligned}
& L q=40 \text { Pasien } \\
& \rho=2.0004128
\end{aligned}
$$
antrian adalah 40 pasien.

4. Rata-rata jumlah pasien didalam sistem

$$
\begin{aligned}
& L s=L q+\left(\frac{\lambda e f f}{\mu}\right) \\
& \lambda \text { eff }=\lambda\left(1-\rho_{n}\right) \\
& \lambda \text { eff }=48.45(1-0.0043627) \\
& \lambda \text { eff }=48.238 \\
& L s=40 \frac{48.238}{24.22} \\
& L s=66.45 \text { Pasien }=66 \text { pasien }
\end{aligned}
$$

5. Waktu rata-rata yang dihabiskan pasien dalam antrian tersebut (untuk menunggu) :

$W q=\frac{L q}{\lambda e f f}$

$W q=\frac{40}{48.238}=0.829 \mathrm{Jam}$

Rata-rata waktu pasien menunggu dalam antrian adalah 0.829 jam (49.75 menit)

6. Waktu menunggu yang dihabiskan pasien dalam sistem antrian (menunggu dan dilayani)

$$
\begin{aligned}
& W s=W q+\frac{1}{\mu} \\
& W s=0.829+\frac{1}{24.22}=0.870 \mathrm{Jam}
\end{aligned}
$$

Rata-rata waktu pasien menunggu dalam antrian menunggu dan

1. Probabilitas tidak adanya pasien dalam sistem adalah :

$$
\begin{aligned}
& P_{0}=\left[\sum_{n=0}^{c-1} \frac{\rho^{n}}{n^{!}}+\frac{\left(1-\left(\frac{\rho}{c}\right)\right)}{\left(1-\left(\frac{\rho}{c}\right)\right)}\right] \\
& P_{0}=0.00479573
\end{aligned}
$$

Jadi probabilitas tidak terdapatnya pasien dalam sistem antrian (loketmenganggur) adalah $0.00479573(0.479573 \%)$

2. Probabilittas sistem penuh

$$
\begin{aligned}
& P_{n}=\frac{\rho^{n}}{n !} P_{0} \\
& P_{93}=\frac{2.0004128^{93}}{93 !} X 0.00479573 \\
& P_{93}=4.185350=0.0004185350
\end{aligned}
$$

Probabilitas sistem penuh adalah $0.0004185350(0.04185350 \%)$

3. Rata-rata jumlah pasien didalam antrian

$$
L q=28 \text { Pasien }
$$

Jadi rata-rata pasien berada didalam antrian adalah 28 pasien.

4. Rata-rata jumlah pasien didalam sistem 


$$
\begin{aligned}
& L s=L q+\left(\frac{\lambda e f f}{\mu}\right) \\
& \lambda \text { eff }=\lambda\left(1-\rho_{n}\right) \\
& \lambda \text { eff }=48.45(1-0.0004185350) \\
& \lambda \text { eff }=48.429 \\
& L s=28 \frac{48.429}{24.22} \\
& L s=55.988 \text { Pasien }=56 \text { pasien }
\end{aligned}
$$

5. Waktu rata-rata yang dihabiskan pasien dalam antrian tersebut (untuk menunggu) :

$W q=\frac{L q}{\lambda e f f}$

$W q=\frac{28}{48.429}=0.578 \mathrm{Jam}$

Rata-rata waktu pasien menunggu dalam antrian adalah 0.580 jam (34.68 menit)

6. Waktu menunggu yang dihabiskan pasien dalam sistem antrian (menunggu dan dilayani)

$$
\begin{aligned}
& W s=W q+\frac{1}{\mu} \\
& W s=0.578+\frac{1}{24.22}=0.619 \mathrm{Jam}
\end{aligned}
$$

Rata-rata waktu pasien menunggu dalam antrian menunggu dan dilayani adalah 0.619 jam $(37,14$ menit)

Setelah dilakukan perhitungan parameter antrian sistem antrian saat ini dan sistem antrian usulan, maka dapat dilihat perbedaan karakteristik pada tabel dibawah ini :

Tabel 3 Perbedaan Karakteristik Sistem

Antrian Saat Ini Dan Sistem Antrian Usulan

\begin{tabular}{|l|l|l|}
\hline \multicolumn{1}{|c|}{$\begin{array}{c}\text { Ukuran } \\
\text { Performasi } \\
\text { Antrian }\end{array}$} & \multicolumn{1}{|c|}{$\begin{array}{c}\text { Sistem Antrian } \\
\text { saat ini }\end{array}$} & $\begin{array}{c}\text { Siste } \\
\text { m } \\
\text { Usula } \\
\mathbf{n}\end{array}$ \\
\hline $\begin{array}{l}\text { C (Jumlah } \\
\text { Pelayanan / } \\
\text { Server) }\end{array}$ & 3 Loket & 4 \\
\hline$P_{0}$ & 0.0049989 & 0.0047 \\
\hline
\end{tabular}

\begin{tabular}{|l|l|l|}
\hline $\begin{array}{l}\text { (Probabilitas } \\
\text { tidak adanya } \\
\text { pasien dalam } \\
\text { sistem) }\end{array}$ & 9573 \\
\hline $\begin{array}{l}P_{93} \\
\text { (Probabilitas } \\
\text { Sistem Penuh) }\end{array}$ & 0.0004362721 & $\begin{array}{l}0.0004 \\
18535 \\
0\end{array}$ \\
\hline $\begin{array}{l}\text { Lq (Rata-rata } \\
\text { jumlah pasien } \\
\text { dalam antrian) }\end{array}$ & 40 Pasien & 28 \\
\hline $\begin{array}{l}\text { Ls (Rata-rata } \\
\text { jumlah pasien } \\
\text { dalam sistem) }\end{array}$ & 66 Pasien & Pasien \\
\hline $\begin{array}{l}\text { Wq (Rata-rata } \\
\text { waktu 49.75 Menit } \\
\text { menunggu) }\end{array}$ & Pasien \\
\hline $\begin{array}{l}\text { Ws (rata-rata } \\
\text { waktu 52.23 Menit } \\
\text { menunggu dan } \\
\text { dilayani) }\end{array}$ & Menit \\
\hline
\end{tabular}

Berdasarkan dari pengolahan data yang dilakukan didapat bahwa panjang anttrian dan pasien dalam mengantri sudah berkurang dari yang sebelumnya. Secara persentase besarnya pengukuran tersebut adalah :

1. Pengukuran Panjang antrian (\% Lq)

$$
\% L q=\frac{40 \text { Pasien }-28 \text { Pasien }}{40 \text { Pasien }} \times 100 \%=30 \%
$$

2. Pengukuran Panjang Antrian Dalam Sistem (\% Ls)

$$
\% L s=\frac{66 \text { Pasien }-56 \text { Pasien }}{66 \text { Pasien }} X 100 \%=15.15 \%
$$

\section{KESIMPULAN}

Keimpulan :

1. waktu optimal yang diperoleh pada loket pendaftaran pasien di Puskesmas Padang Pasir adalah sebesar 177 detik.

2. Sistem antrian yang optimal pada loket pendaftaran pasien berdasarkan perhitungan yang dilakukan pada penelitian ini diusulkan ada penambahan 1 petugas loket sehingga loket pelayanan menjadi 4 untuk mengurangi antrian panjang diloket pendaftaran. 


\section{DAFTARA PUSTAKA}

Taha, Hamdy A, 1996,Riset Operasi Jilid Dua, Binarupa Aksara, Jakarta.

Walpole, Ronald E, 1982, Pengantar Statistika Edisi Ketiga, PT. Gramedia Pustaka Utama,Jakarta.

Wiguna, Andri, 2010, Optimasi Performansi Sistem Antrian Pelanggan Terhadap Pelayanan Teller Pada Perusahaan Daerah Air Minum (PDAM) Padang, Sekolah Tinggi TeknologiIndustri (STTIND), Padang.

Zulfikarijah, Fien, 2004, Operation Research. Edisi Pertama Cetakan Kedua,Bayu Media

Publishing,Malang. 